\title{
Certainty Certainly Not Protocols Of Change: Knowledge, Power, and Authority In Architecture and Science
}

\author{
SHERRY BATES \\ South Bank University \\ United Kingdom
}

\section{INTRODUCTION}

As architects and historians of architecture we are all acquainted with major sea changes in our discipline. The birth of Modernism and the advent of Post modernism' are two episodes of our recent history familiar to most of us. Customarily however we focus upon the content of such changes rather than the protocols they obey. I talk of protocols rather than rules because I shall argue that these are not a natural given but a product of cultural ${ }^{2}$ propriety. It is my thesis that there are protocols for such changes, which if not invariant are subject to modifications themselves that are only manifest over long periods of time. I further contend that the structures of the institutions of architecture, the building industry, the profession, the academy and the architectural press for example and of their relation to culture at large have a more powerfully formative influence on the nature of such changes than any individual, group or movement. This paper can provide but a mere outline and brief illustration of these broad claims.

To investigate them here I shall compare the construction of knowledge and the sources of power in architecture with those in the physical sciences. Henceforth I shall intend the word science to encompass only the physical sciences, principally, physics, chemistry and biology, not the social sciences. I have chosen the physical sciences for comparison because throughout the Twentieth Century they have provided a foundation stone of popular truth. I shall argue that the pluralist cultural contingency of architecture, often perceived as a weakness, may provide an example whereby science might begin to escape its own false objectivity. Further, provided that we are critical about the distinction between the two subjects, the structures and protocols of scientific change may help us establish an initial description for those of architecture.

\section{CHARACTERISTICS OF SCIENTIFIC DEVELOPMENT}

In his book, The Structure Of Scientific Revolutions ${ }^{3}$, Kuhn describes normal scientific development as a steady condi- tion within one set of accepted concepts, which he calls a 'paradigm'. This steady state periodically reaches crisis point when new observations conflict with the existing paradigm. It is then repudiated and supplanted by another, an incident he calls a 'revolution'. The choice of its replacement is made by the community of scientists working in that discipline and is profoundly cultural ${ }^{4}$. He points out

'the insufficiency of methodological directives, by themselves, to dictate a unique substantive conclusion to many sorts of scientific questions, '5

By this he means, there is no scientific method which, without other information being supplied, will, for a given set of experimental results, produce a single conclusion to a scientific question, irrespective of what sort of scientific question that is. He continues:

'Instructed to examine electrical or chemical phenomena, the man who is ignorant of these fields but who knows what it is to be scientific may legitimately reach any one of a number of incompatible conclusions. Among those legitimate possibilities, the particular conclusions he does arrive at are probably determined by his prior experience in other fields, by the accidents of his investigation, and by his own makeup.'

Kuhn's argument denies cumulative scientific development because successive paradigms are irreconcilable. Yet progress does occur because each paradigm must be regarded by the scientific community concerned as more sophisticated than the previous one. However Kuhn does not focus upon the relationship of the scientists with the wider community beyond them. To pursue their concerns all groups must be politically and economically empowered to do so by the wider community. Because of the success of technology in fulfilling popular, corporate and government desires and despite dissident voices, scientific research has been highly prized by the world at large since the second half of Nineteenth Century. ${ }^{7}$ Since then, science has either driven technology or been the senior partner in a condition of interdependency. ${ }^{8}$ Due to the alliance of science, technol- 
ogy, capital and the state formed at that time, scientists have rarely had to struggle to establish a terrain for their subject and have seen their research as the principal agent in the manufacture of this terrain.

It is a protocol that new scientific research present itself in the context of its associated empirical data and the extant body of scientific knowledge only. This research must appear acultural. The forms of its presentation are subject to strict convention in order to lend them a putative neutrality and remove them from its discourse. Although papers are dated and text books may refer to events, scientists generally see and understand that body of knowledge synchronically.

It is a protocol of 'mature' science that only one self consistent, scientific paradigm exist at a given time. If a subsequent theory appears it should be understood as more general and incorporate the former as a special case. ${ }^{9}$ Einstein's Special Theory of Relativity is a prime example. It incorporates the formulations of Newton and Gallileo as a special case applicable when the speeds concerned are small in comparison with that of light. Viewing scientific knowledge as a single entity that must be self consistent further emphasises the presentation of science as a collection of objective facts, despite the philosophical problems with such a concept ${ }^{10}$, and despite the dependency of the subject's own progress upon the heuristic status of its current body of knowledge. That is although at any moment the current body of knowledge is treated as fact it must always be changeable and therefore provisional to allow development of the subject."

Science had moved from being a leisure pursuit of gentlemen by the end of the eighteenth century. A hundred years later it was firmly ensconced in the academy and industry. Since the second half of the nineteenth century most research has been funded by governments and corporations. Although scientific developments are legitimised by the community of researchers in the same field, they would be still born if no funding were available. The direction of research and the rate of change of scientific knowledge reflects concerns of the funding agencies. ${ }^{12}$ The fragmentation of science into smaller subject areas and the detailed nature of experimental investigation make it difficult for the researchers themselves to perceive a strategy for the development of that knowledge larger than and external to their own concerns. Here scientific journalism plays its principle role. It communicates across the divides between subjects and disciplines. However despite their ability to diminish or enhance individual reputations, scientific journalists do not have the power to alter the body of knowledge, except in rare cases. Although these are published in the scientific press, it is through the production of papers by the researchers themselves that the body of knowledge is altered. Historians of science play little part in its development. They occupy a discipline of their own which has much stronger links with the wider community of historians than it does with that of researching scientists. Similarly philosophers of science and mathematicians have their own domain. They do however have an impact on the practice of research and the construction of the body of knowledge by clarifying subject areas, theoretical premises and methods. They play a key role in maintaining scientific disciplines within an accepted framework rooted in mathematics and Western philosophy.

The myth of fact, the acultural emphasis of the presentation of new research and the foregrounded synchronicity of the paradigm make the scientific project at once difficult to challenge and limit the sort of questions that may be asked of it. It is very difficult to address political questions for example.

\section{CHARACTERISTICS OF ARCHITECTURAL DEVELOPMENT}

Architecture like science has 'communities' or vested interest groups which make decisions about the legitimate concerns of the discipline. Architecture by contrast has rarely, if ever, achieved such universal acclaim. Unlike science, architecture has never formed such a powerful alliance with the state and capital. Dangerous liaisons briefly flourished during the time of the Modern Movement but historically the principal players in large scale building programmes have been contractors and entrepreneurial developers. The influence of architects here has been small. Although currently sanctioned as a profession and academic subject, architecture is popularly regarded as a luxury. In consequence its domain has remained small and, in popular perception, is Cultural with a large " $C$ " rather than of everyday importance. There is an immense discrepancy between the popular perception of architecture and its perception by architects themselves.

The community of architects readily accepts that its development is contingent upon the action of a wider culture. It is a protocol that new developments in architecture be presented as a response to such contingencies: political events, social changes, economic circumstance, scientific advances, technological developments, new ideas in philosophy, music, fine art, the decorative arts, industrial design, film or advertising.

Further for many architects the identification of a body of knowledge and focus for the subject has been and is a problem. Therefore it has been rare for the community of architects to adopt an integrated pursuit of their discipline. Architects have seen themselves variously as: chief builders, surveyors, gentlemen, businessmen, artists, purveyors of professional services, social engineers, industrial designers and academics. Each of these roles brings a different view of what architecture and its practice are, some of them at times have appeared mutually exclusive. There is a protocol that architectural knowledge be understood as ideological rather than factual.

However these works are economically interdependent. Without the presence of the profession and the building industry departments of architecture in universities would be much smaller. What gives the profession of architects 
authority however? Why architectural creativity, that indefinable something. The power of this notion is that it is popularly understood to be more easily recognised than described, but this view leaves far too much to chance. So that it is not undermined, the profession creates the illusion of removing the arbitrariness attached to the application of this label. How is this done? The social context and history ${ }^{13}$ of creativity is emphasised. Technical expertise is stressed. The art of construction has been a source of legitimization for the architect's expertise since Vitruvius. Techniques of construction were slow to develop until the Industrial Revolution. The subject matter of the art of construction was therefore relatively static up to that time. It has only been within the last 150 years that technological development has been invoked as the contingent driving force of significant architectural change. ${ }^{14}$ But whatever a practising architect's personal stance on the relationship of architecture and technology the technical expertise associated with the construction of buildings is regarded by him or her as a corner stone of architectural creativity. Theories are constructed for creativity. These usually concern technique, method or interpretation or perhaps they might contextualize it socially or historically,... Zeitgeist for example. The members of the 'creative' profession must also undergo a 'creative' education. Formerly this was by apprenticeship. More recently it has been located in the academy. The existence of the academy has an advantage to the profession. It is associated with another institution the universities. Therefore it is seen as an agent of legitimation external to the profession itself. It is a protocol that the best creative product of the academy is as far removed as possible from the work of the mainstream architects who earn their living by designing buildings for fee paying clients. Preferably the best creative product should be incomprehensible to them. This is where certain 'academic'architects take command. Their work $a$ is seen as speculative and exuberant. That the public may find it difficult to relate this work to most contemporary buildings around them only lends it more power, that of mystique. The argument of the mainstream architect may be that this is not architecture but the mystique is none the less useful to them and despite complaining about their lack of technical expertise relevant to practice, they are mostly happy to employ the students of these academics.

The mystique of creativity is reinforced by the genius myth and the aura of originality. Geniuses are made demigods in both science and architecture but in architecture their work is customarily revisited as a source of creative mastery and authority. The label genius is applied by others, preferably when the beatified person is already dead ${ }^{15}$ This historical aspect establishes standards in the present which are not those of the genius alluded to but which are mythical and therefore unattainable. In the present comparisons are made by others ${ }^{16}$ critics, of works by a contemporary author with the oeuvre of an acknowledged genius' in order occasionally, to applaud and sometimes, to belittle. Those applauded become the stars, the signature architects, the authors of really creative works and possibly the geniuses of tomorrow. The signature is the mark of creativity and originality ${ }^{17}$. It is therefore a protocol that the authorship of all works by architects is clear.

However 'Creativity' is not totally subjective. That which is created is characterised by: who, what, where, when and with what; who made it, with what materials, what techniques, what they were thinking at the time, where they made it, when they made it and what was happening in the world at that moment. This presents architects, whether in the academy or the profession, with two problems; firstly how to label these multifarious products and secondly how to make links between them in order to give architecture an identity. It is a protocol therefore not only that architectural works themselves be presented as authored and partial but that major sea changes in architectural thinking be so presented. Manifestos for example abound in architecture but are rare in science. The naming of a movement takes place instead of the establishment of a paradigm and several movements may exist simultaneously. At once this provides a method of labelling and lays bare the profoundly cultural, site specific nature of the activity called architecture.

Coining the names of movements is often the prerogative of the historian or theoretician. Historians play a key role in maintaining the political authority of architecture by lending coherence to the fragmentary pursuits of individual architects. The historian has a vested interest in doing this as to do so successfully, which means principally having convinced the community of architectural historians, theoreticians and architects in academia, establishes his or her credentials as a historian. Since the production of newspapers and magazines has become relatively cheap, architectural journalists and journalists generally have had more influence as arbiters of the discipline, than: practising architects, historians or theoreticians. Further, the advent of mass telecommunication has provided a new coterie of individuals with influence, the presenters. Television has removed the mystique from many specialist subjects, including architecture. This has lead to less deference by the wider community.

\section{CONCLUSION}

My purpose in giving this paper has been to shed light on the location of architecture and the limits of that location within the realm of human endeavour. I have also argued that science far from a foundation stone of truth in contemporary life, is a profoundly cultural entity.

We have seen how the production of science is strictly delimited according to the following protocols:

1) The metastructures of scientific knowledge remain rooted in mathematics and Western philosophy.

2) Scientists perceive that body of knowledge as a single totalised and progressing entity.

3) Forms of scientific representation are constructed to present it as unassailable, objective fact derived from 
particular observations of the universe and free from social history or cultural interpretation.

4) The education of the scientist is largely consensual and deeply engrains those metastructures and forms of representation in the student early in his or her career.

5) Amongst the occupational roles of people within the scientific community it is the researchers who are responsible for the construction of the body of knowledge.

6) The success of technology has lent science enormous popular support and despite the widely different perceptions of the discipline by scientists themselves and those outside the scientific community, scientists are largely able to determine what science is if not the direction of research.

7) Although popularly conceived as an objective subject elaborated through the observation of the universe the scientific body of knowledge is shaped and directed by the interests of institutions which fund research.

The protocols of architecture are not the identical to those of science.

1) The metastructures of architectural knowledge are rooted in history, custom and the exigencies of constructional practicalities.

2) Architects see their subject as pluralist. Although the notion of progress is currently embraced by some and has been significant historically, the freshness of a particular architect's creativity has generally been more important. Change is seen as culturally contingent rather than as the act of perfecting a definable body of knowledge. Creativity although presented as the product of individuals is culturally prefigured.

3) Architectural representations although subject to historically constructed orthodoxies must generally express subjectivity and authorship in their form rather than suppress it. Even drawings of the most inexpressive architecture reveal the hand of authorship.

4) The education of the architect has had its consensual moments ${ }^{18}$ but rarely without a reaction to them. Historically it has been a protocol of architectural education that the student challenge the existing view of the subject.

5) People in all the occupational roles associated with architecture construct its identities. There is some interdependency between these identities. Currently journalists are more influential in this than the architect or historian.

6) A huge gulf exists between the popular perception of what architecture is and how the members of its institutions see it. In the contemporary world those from without architecture increasingly set its agenda in practice.

7) The architecture of practice is principally shaped by the institutions that fund the production of buildings and by the industries which supply the materials and construction expertise. The world of practice and the building industry has an impact within the architectural school but so also do those activities which are part of the culture industry ${ }^{19}$. The world of the architecture school has historically had little impact upon the practice of building.

A profound relativism abounds in our culture, sponsored by the ever more sophisticated media. The authority of architects, amongst many other experts has been successfully challenged. This relativism has invaded architecture itself. This is not just reactive introspection but facilitated by the site specific nature of the activity of the discipline. Science supplanted religion, at least in the Western World, as the principal source of popular truth in the Nineteenth Century. Since that time, the consensus of science has continued to uphold and reproduce the power of the organs that fund it. In the post nuclear age its contradictory apolitical self-presentation and deeply political nature have been revealed ${ }^{20}$. It has been and is fairly easy for science to provide the master narrative of truth. Its discourse takes place principally in one of the least site specific forms in human endeavour, mathematics. It is further a postulate that the laws of science obtain everywhere.

I would like to finish this paper by asking some questions. How long will science continue to supply the master narrative of truth? What will challenge it? Will developments in information technology, themselves based on mathematical structures reinforce it? Will the profound culturalism and relativism of media society, including architecture, finally impact on the false objectivity of the scientific project? What limits do the protocols of architectural change place upon our influence in 'defining the urban condition'?

\section{NOTES}

1 In this context I use these terms in their architectural sense only.

2 Here culture is used in an anthropological sense to describe the material and signifying production associated with the development of human existence. Later it is invoked with a capital 'C' to denote "high' art.

3 Thomas S Kuhn The Structure Of Scientific Revolutions, The University Of Chicago Press 1962

4 Although there exist a variety of theories of scientific development, the points on which they differ are largely clear. I appeal to Kuhn here principally for the manner in which he uses the history of science to reveal science itself as a cultural construction rather than for the particular model of scientific development that he elaborated. A discussion of the differences between this model and those of other theoreticians, such as Popper for example is outside the scope of this paper.

${ }^{5}$ Op Cit. p 4

${ }^{6}$ Op Cit. p 13. Kuhn describes three eighteenth century theories of electricity; electricity viewed as a fluid, electricity conceived as attraction and repulsion, and a third theory that related electrical phenomena to frictional generation. Each of these was compatible with experimental data but each provided ultimately irreconcilable models.

7 'The technical innovations introduced into engineering and industry generally up to about 1850 were not greatly dependent on the content of the science then known. By contrast, science gained considerably from the investigation of engineering problems in certain cases, such as thermodynamics which developed in part from the study of the steam engine. After 1850 , the application of science to the development of technology became a more and more important factor in the advance 
of industry, during the present century most of the outstanding technical discoveries stemmed in the main from scientific researches.' Stephen F Mason A History of The Sciences Macmillan NY 1962 p503

${ }^{8}$ Prior to 1850 , it may be argued that the reverse was the case. Scientific development was lead by those in technology, particularly in the field of precision engineering by such people as , Brahmah, Maudsley, Clement and Whitworth. The ability to make screw threads and flat surfaces precise to less than one thousandth of an inch enabled the construction of a new breed of experimental apparatus.

${ }^{9}$ The impossibility of deciding whether light is best described as a wave or particle, almost brought late nineteenth century physics to a crisis. It was resolved by the development of a Quantum Mechanics which states that under certain circumstances things we think of as particles may act like waves and things we regard as waves may act like particles, thus presenting waves and particles as alternative descriptions of the same entity. This duality still presents the scientific community with philosophical problems.

10 This is a whole subject area in its own right.

11 Moreover research is a fundamental activity to the community of scientists. Therefore they have a vested interest in seeing their project as something infinitely extendible.

12 Stephen F Mason (Op Cit. p 435 ) discusses the change in French science promoted by the new regime after the French Revolution.

13 Architectural history is a double edged sword however. When viewing the history of their subject, there is a tendency for architects to reify a particular small set of artefacts and events.
${ }^{14}$ From the time of Joseph Paxton's Crystal Palace of 1851. (It is probably not a coincidence that this juncture is coeval with the hegemonic ascendancy of science I described earlier). Since then technological development has metamorphosed from an engine of architectural modernity; a notion espoused from the time of Viollet Le Duc's Structural Rationalism, outlined in his lectures of 1853, at least until Stirling and Gowan's Engineering Building at Leicester University of 1959 ; to become a self conscious generator of an aesthetic which fetishises the machine rather than expresses function. This is characterised by the development of High Tech Architecture.

15 This is a protocol of all endeavours not just architecture and science.

${ }^{16}$ In the present, allusion to a genius may also be employed positively by individual architects or theoreticians themselves citing the ideas or work of that genius.

17 Also of ownership and legal responsibility but that discussion lies outside the scope of this paper.

${ }^{18}$ For example the Ecole Nationale Supérieure De Beaux Arts provided the dominant European model for architectural education during the nineteenth century.

19 'Culture industry' is used here to denote those activities whose products are consumed as leisure or surplus rather than as subsistence prerequisites.

20 Instead of generating a crisis for the scientific project this has accelerated that project. The effects of science and its handmaiden technology, revealed as neither benign nor neutral, have been resolved by asserting that neutrality more vigorously through the separation of the problem into political issues, defined as 